\title{
ESTIMATIVA DA RECARGA DAS ÁGUAS SUBTERRÂNEAS NO SISTEMA AQUÍFERO BAURU (SAB)
}

\author{
GROUNDWATER RECHARGE ESTIMATES AT BAURU AQUIFER SYSTEM (BAS)
}

\author{
Vitor Fidelis Monteiro Gonçalves ${ }^{1}$, Rodrigo Lilla Manzione ${ }^{1}$ \\ ${ }^{1}$ Universidade Estadual Paulista Júlio de Mesquita Filho (UNESP), Tupã, SP, Brasil
}

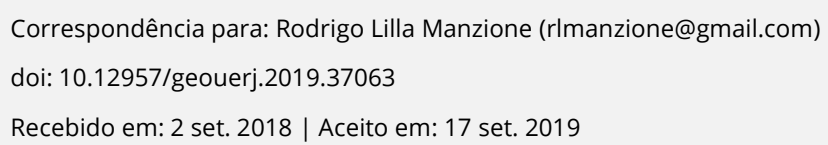

\section{RESUMO}

Estimar os valores de recarga das águas subterrâneas é importante para entender a dinâmica de sistemas aquíferos perturbados por forçantes climatológicas e pelo uso e ocupação da terra. Este trabalho estimou as taxas de recarga das águas subterrâneas pelo método da variação da superfície livre em área do Sistema Aquífero Bauru (SAB) para a Estação Ecológica e na Floresta Estadual de Santa Barbara nos anos hidrológicos 2014/2015 e 2015/2016. Durante esse período a região passou por dois períodos climáticos distintos: um ano considerado normal (com taxas de precipitação em torno da média histórica dos últimos 30 anos) seguido de um ano com a presença do fenômeno ENOS (El Niño Oscilação Sul) aumentando a precipitação em 35,44\% quando comparado ao ano anterior. Os resultados demonstraram, apoiados na espacialização do fenômeno pela área estudada, que apesar das diferenças nas taxas de precipitação, o percentual de recarga foi o mesmo para os dois anos, não evidenciando diferenças entre as áreas com vegetação de Cerrado e reflorestamentos com espécies exóticas como Pinus e Eucalipto.

Palavras-chave: método da variação da superfície livre, monitoramento, ENOS, geoprocessamento, lençol freático.

\begin{abstract}
Estimating groundwater recharge values is important to understand aquifer dynamics disturbed by climatological driven forces and land use. This work estimated groundwater recharge rates using water table fluctuation method in a Bauru Aquifer System (BAS) area at Santa Barbara Ecological Station and State Forrest for 2014/2015 and 2015/2016 hydrological years. During this period, the area passed through two distinct climate periods: first, a considered normal year (with precipitation rates around the historical 30-year mean), followed by a year with the presence of ENSO (EI Niño South Oscilation) increasing precipitation $35.44 \%$ if compared with the previous year. The results showed, spatializing the phenomenon in study area, which even with differences in the precipitation rates, the percentage of recharge was the same for both periods, not evidencing differences from areas with Cerrado vegetation and exotic reforestations with Pine and Eucalyptus trees
\end{abstract}

Keywords: water table fluctuation method, monitoring, ENSO, geoprocessing, water table.

\section{INTRODUÇÃO}

A estimativa da recarga de águas subterrâneas é um fator importante a ser estudado pelos tomadores de decisão ao que tange o gerenciamento dos recursos hídricos. A recarga das águas subterrâneas representa a parcela de água da precipitação que se torna recurso viável ao uso, visto que é a parcela de água que atinge o lençol freático e se torna parte do sistema aquífero. 
Existem diversos métodos para estimar a recarga das águas subterrâneas e a escolha do método ideal depende dos objetivos do trabalho a ser desenvolvido e da precisão que se espera dos resultados, além das possibilidades econômicas e de disponibilidade de equipamentos. Segundo Healy (2010), os métodos para estimar a recargas podem ser divididos em: (i) métodos de balanço hídrico, (ii) métodos baseados em estudos de interação com águas superficiais, (iii) métodos baseados em estudos da zona não saturada, e (iv) métodos baseados em estudos da zona saturada. Os métodos baseados em estudos sobre a zona saturada abrangem amplas áreas e geralmente preveem recarga atual, visto que a água precipitada atinge o lençol freático. Dentre os principais métodos para os estudos voltados a zona saturada destacamse o método da variação da superfície livre, métodos baseados na Lei de Darcy e métodos que utilizam traçadores históricos e ambientais (SCANLON et al., 2002). Hocking e Kelly (2016) mediram o tempo da taxa de recarga utilizando funções de resposta-impulso. Niazi et al. (2017) estimaram a distribuição espacial da recarga de águas subterrâneas através do fluxo de base e energia. Gemtzi et al. (2017) desenvolveram equações para a recarga das águas subterrâneas mensalmente baseado em modelagem com dados de sensoriamento remoto. Keesari et al. (2017) fizeram uma investigação sobre a recarga e as dinâmicas das águas subterrâneas utilizando técnicas isotópicas. Já estudos como o de Han et al. (2017) encontraram alterações na recarga das águas subterrâneas por causa das mudanças antropogênicas na paisagem enquanto Tabau et al. (2017) quantificaram a recarga das águas subterrâneas em ambientes urbanos.

Mesmo com desenvolvimentos em diversas áreas do conhecimento, a estimativa da recarga ainda gera muitas incertezas no que tange seus valores, visto que, a maioria dos modelos atualmente utilizados depende de muitos dados. Dados estes que podem trazer uma grande quantidade de erros já que a recarga é um fenômeno com elevada variabilidade espacial devido as diferenças geológicas, climatológicas e de uso e ocupação da terra (MANZIONE, 2015). Estimar taxas de recarga permite entender o comportamento de um aquífero frente à forçantes climatológicas e modificações no uso e ocupação da terra, podendo assim planejar as atividades e melhorar a tomada de decisão em sistemas agrícolas e ambientais. Esse desafio faz ao gestor buscar métodos mais precisos e equipamentos mais aferidos para melhorar a contribuição de seus estudos aos planos de recursos hídricos de determinada região. Entretanto, essa estimativa pode ser influenciada por fenômenos climáticos específicos como o ENOS 
(El Niño Oscilação Sul) como reportado em Susilo et al. (2013), onde os autores analisaram as oscilações das águas subterrâneas de 4 poços na Indonésia sob influência do ENOS, e em Ferrer et al. (2019), onde os autores fizeram uma análise hidrodinâmica das águas subterrâneas na costa leste do continente africano durante os eventos da La Niña 2016/17 e do ENOS no período anterior.

Neste contexto, o objetivo desse trabalho foi estimar a recarga das águas subterrâneas pelo método da variação da superfície livre para entender o comportamento do Sistema Aquífero Bauru (SAB) em diferentes condições climáticas e de uso e ocupação da terra na Estação Ecológica e na Floresta Estadual de Santa Barbara, Águas de Santa Barbara/SP nos anos de 2014/2015 e 2015/2016.

\section{PROBLEMA EM ESTUDO}

Durante o verão dos anos 20013/2014, o Estado de São Paulo passou por um dos períodos mais secos já registrados (CPRM, 2014, COELHO et al., 2016), trazendo efeitos diretos no ciclo hidrológico. No tocante às águas subterrâneas, isso pode levar a diminuição da recarga dos aquíferos e a consequente produção de água em nascentes, contribuindo ainda mais para o quadro de escassez hídrica (VALENTE e GOMES, 2005).

Já entre 2015 e 2016, o mundo presenciou um dos fenômenos El Niño Oscilação Sul (ENOS) mais fortes já registrados, aumentando as precipitações no inverno (CPRM, 2015). Os impactos dos eventos El Niño e La Niña sobre o Sul da América do Sul trazem dificuldades nos setores hidrológico (BOULANGER et al., 2005) e agrícola (PODESTÁ et al., 1999), particularmente sobre o nordeste da Argentina, a parte mais meridional do Brasil e do Uruguai (PENALBA e RIVERA, 2016). Segundo Spescha et al. (2004), o excesso de precipitação associado aos eventos El Niño contribui para teores excessivos de água observados nos solos da região Pampeana da América do Sul. Penalba et al. (2014) reportaram um aumento de cerca de 10\% no armazenamento de água no solo sob tais condições na Argentina. Nesse último evento, diversos locais tiveram seus regimes de precipitação alterados, como no interior do Estado de São Paulo onde áreas de clima subtropical tipicamente com verão chuvoso e inverno seco tiveram um 
inverno chuvoso, favorecendo a recuperação dos mananciais superficiais e subterrâneos afetados em 2013/2014 já em 2015/2016 (SANTAROSA, 2016; MANZIONE, 2017).

Na região Hidrográfica do Médio Paranapanema (UGRHI-17), as águas subterrâneas são fonte de abastecimento de diversas cidades, de inúmeras nascentes e dos principais rios que suportam sistemas agrícolas e florestais, além de remanescentes de Cerrado. O SAB é um dos principais mananciais subterrâneos disponíveis na UGRHI-17 (CBH-MP, 2010). Frente a esse cenário, procurou-se estimar a recarga das águas subterrâneas em uma área de conservação e reflorestamento no SAB para dois períodos distintos de precipitação, os anos hidrológicos de 2014/2015 e 2015/2016, procurando entender a influência do clima e do uso da terra nesse processo.

\section{MATERIAL E MÉTODOS}

\section{Área de estudo}

A Estação Ecológica de Santa Barbara (EEcSB) foi regulamentada pelo Decreto 22.337 de 07 de junho de 1984 que instituiu sua formação com uma área de 4.371 hectares dentro dos limites da Floresta Estadual de Santa Bárbara, dos quais apresentam uma área 2.712 hectares de vegetação nativa (Cerrado, brejos e mata de galeria) dividindo o espaço com o reflorestamento com pinus e eucalipto (Figura 1) 


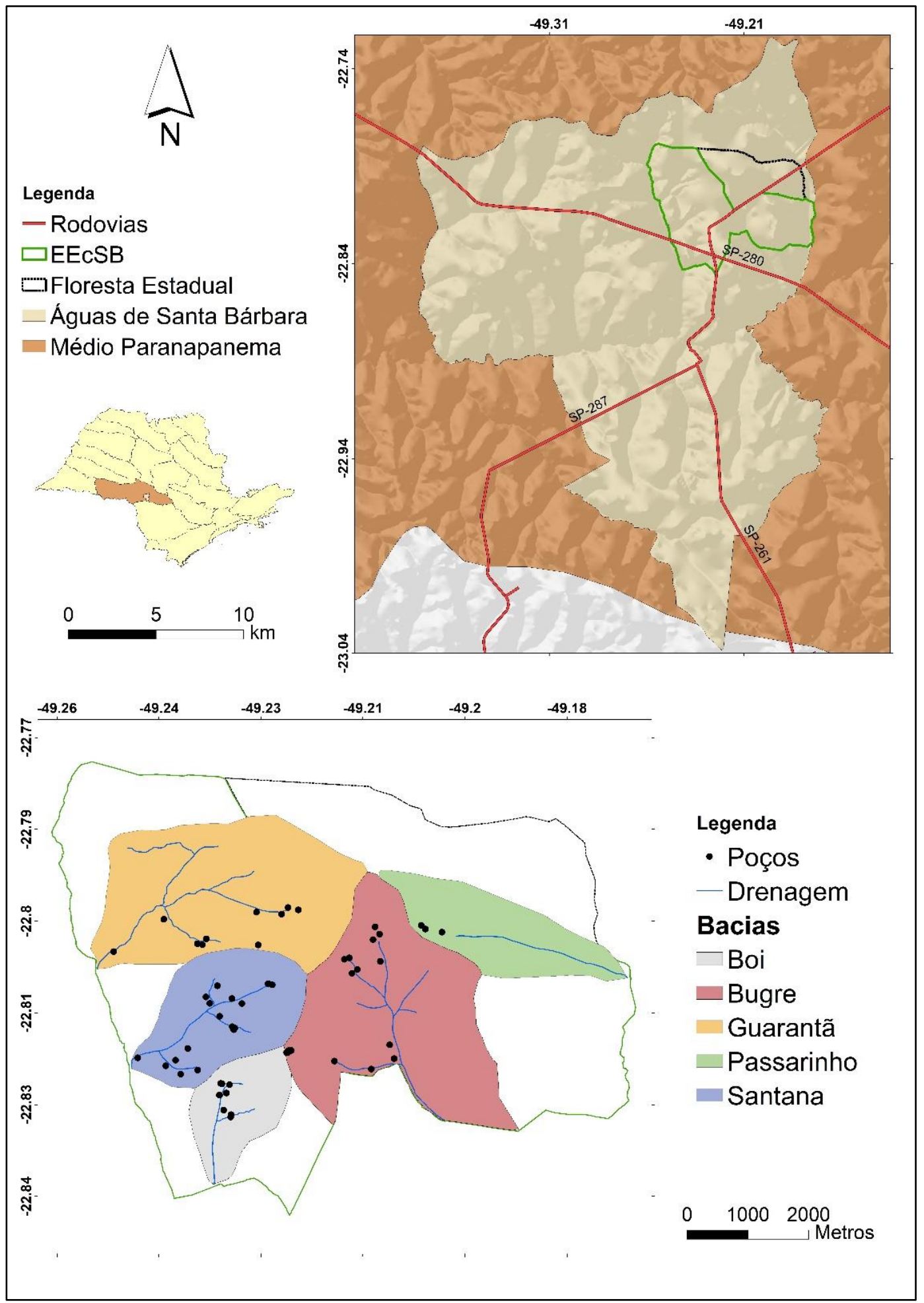

Figura 1. Localização da área de estudos Fonte: Elaborado pelos autores.

As formações geológicas na região são os arenitos da Formação Adamantina e da Formação Marilia, pertencentes ao Grupo Bauru, com predomínio da formação Adamantina na EEcSB (MELO e DURIGAN, 2011; CPRM, 2006). Segundo Ross e Moroz (1996), a EEcSB encontra-se localizado na Bacia Sedimentar do Paraná (morfoestrutura) e no Planalto Ocidental Paulista (morfoescultura), com 
formas de relevo predominantemente de colinas amplas e baixas, com altitudes entre 556 e $705 \mathrm{~m}$ (SANTAROSA, 2016).

O clima característico da região, segundo a classificação de Koeppen, é Cwa ou tropical subúmido (clima quente com inverno seco), apresentando temperaturas de $16^{\circ} \mathrm{C}$ no mês mais frio e $23^{\circ} \mathrm{C}$ no mês mais quente (CEPAGRI, 2016). As precipitações anuais estão em torno de 1000- $2086 \mathrm{~mm}$, podendo chegar a $30 \mathrm{~mm}$ mensais no inverno. A temperatura média anual está em torno de $18^{\circ} \mathrm{C}$, com máximas em janeiro entre $22^{\circ} \mathrm{C}$ e $30^{\circ} \mathrm{C}$ e mínimas no mês mais frio $18^{\circ} \mathrm{C}$ (Melo e DURIGAN, 2011).

\section{Dados disponíveis}

Os dados de oscilação dos níveis freáticos foram obtidos durante dois anos hidrológicos, compreendendo o período de 2014 a 2016. Considera-se como ano hidrológico o período que se inicia em 22 de setembro, no equinócio advindo junto com a primavera, e se encerra em 21 de setembro do outro ano com o final do inverno. Período esse que perpassa as quatro estações do ano, iniciando-se com as primeiras chuvas da primavera. Para fins práticos, adotou-se nesse trabalho como ano hidrológico o período de 12 meses iniciado em setembro e encerrado em agosto do ano subsequente.

Para análise dos níveis freáticos, foram utilizados os dados de 50 poços de monitoramento distribuídos nas Bacias do Guarantã, Bugre, Santana, Boi e Passarinho, perfurados exclusivamente para analisar os níveis freáticos da EEcSB. Os poços foram monitorados com uma frequência quinzenal a partir de 05 de setembro de 2014 até 29 de outubro de 2015, quando se passou a realizar as medições de nível com frequência mensal até 02 de setembro de 2016. Essa mudança deu-se por fins econômicos, uma vez que após um ano monitorando os poços, percebeu-se que não havia grandes oscilações no espaço de duas semanas. Os poços possuem profundidade heterogênea, variando de 2,94 a 7,68 metros.

Os dados climatológicos utilizados nesse estudo foram séries históricas de precipitação registrada em pluviômetro localizado na EEcSB desde setembro de 1987. São séries mensais com o total precipitado no período, totalizando 30 anos de observações para análise até agosto de 2017. 


\section{Estimativa da recarga}

O método da variação da superfície livre (Water Table Fluctuation Method - WTF) foi utilizado nesse estudo por ser um método amplamente utilizado na área acadêmica para se estimar dados de recarga das águas subterrâneas (MOON et al., 2004; MARÉCHAL et al. 2006; WANG et al., 2014; LUCAS e WENDLAND, 2016; COELHO et al., 2017). Esse método parte da premissa que a oscilação do nível piezométrico dos aquífero não confinados está diretamente relacionado às quantidades de água que atingem esse nível (SCANLON et al., 2002). Healy (2010) parte da afirmação acima e do pressuposto de que a quantidade de água disponível em uma coluna de uma unidade de área é igual ao rendimento específico vezes a altura de água na coluna. Assim, a partir de tais conceitos é possível desenvolver a equação fundamental do método da variação da superfície livre da seguinte forma:

$$
R=S_{y} \cdot\left(\frac{\Delta H}{\Delta t}\right)
$$

em que, $R$ é a recarga $(\mathrm{mm})$ do poço observado, $S_{y}$ é o rendimento específico ( - ) do aquífero, $H$ é a altura do nível freático (m) analisado e $t$ é o tempo de ocorrência da recarga (dia, mês, ano). $O \Delta H$ é obtido a partir da diferença entre o pico de ascensão do nível freático e a base da linha extrapolada da última curva de recessão (Figura 2). Este valor é então inserido a fórmula, onde se obtém o valor da recarga parcial daquele pico. A soma das recargas é o que determina a recarga total para o período analisado (HEALY, 2010). 


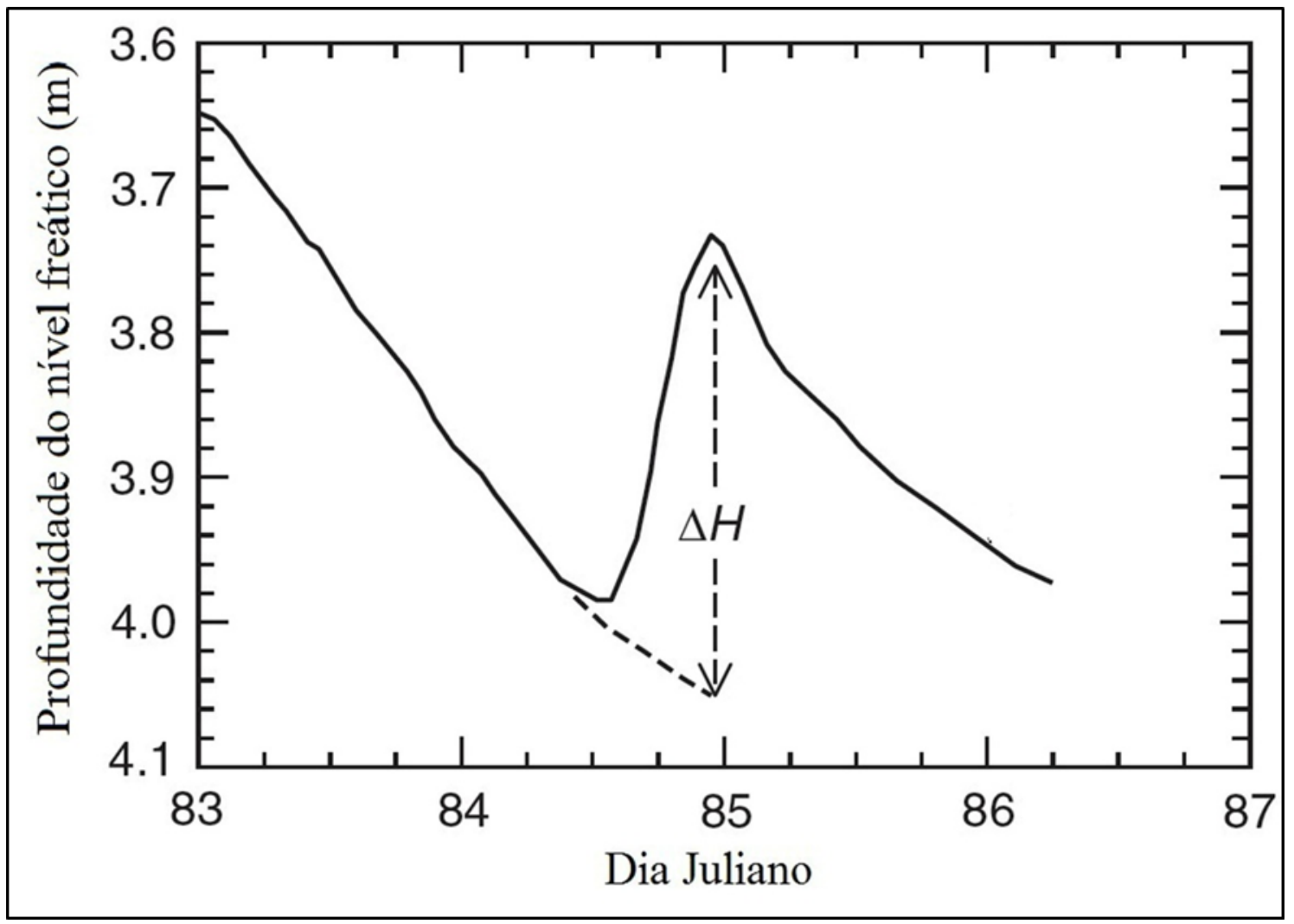

Figura 1: Hidrógrafa hipotética de um poço de monitoramento de água subterrânea. $\Delta \mathrm{H}$ é a diferença entre o traçado da extrapolação da curva de recessão antecedente até o instante do pico (linha pontilhada). Adaptado de: Healy (2010).

Segundo Scanlon et al. (2002) é um método simples e fácil de se utilizar, visto que a presença de fluxo preferencial não restringe o método, pois considera o movimento da água pela zona não saturada. A linha extrapolada da curva de recessão antecedente representa o traçado que o nível piezométrico teria seguido se não houvesse a elevação do mesmo em decorrência da precipitação. A linha pode ser desenhada manualmente, um processo que denota tempo e tende à subjetividade, mas que acomoda certa intuição hidrológica. Entretanto, no panorama atual existe tecnologia suficiente para ajudar o autor a cria-la digitalmente. Essas técnicas automáticas são eficientes com períodos maiores de análise e reduzem a subjetividade do método. Ainda é possível dentro do método, encontrar os valores de armazenamento subterrâneo, substituindo-se na equação: o $\Delta \mathrm{H}$ por $\Delta \mathrm{Hn}$, que representa a carga hidráulica no início e no final de cada período analisado, a diferença encontrada entre a recarga e a variação do armazenamento subterrâneo está na soma da evaporação das águas subterrâneas, o fluxo de base e o fluxo em subsuperficie na área analisada (HEALY, 2010). 
O método da variação da superfície livre tem melhor desempenho quando aplicado em períodos de tempo curto em aquíferos rasos, porém o método pode ser aplicado na análise da magnitude na variação do nível freático em resposta ao clima ou uso da terra, visto que a flutuação do nível piezométrico é a resposta à recarga média (SCANLON et al., 2002). 0 método possui algumas limitações, as taxas de recarga podem variar substancialmente em áreas amplas por inúmeros fatores, como diferença na elevação do terreno, geologia, declividade, vegetação entre outros. Assim como, nem todas as elevações no nível freático representam recarga, esse aspecto pode ser encontrado em locais onde as taxas de recarga e descarga do aquífero são próximas. As incertezas quanto ao método ainda podem vir da dificuldade em estimar o valor do rendimento especifico, pois o mesmo pode variar em relação a profundidade do nível freático, e em longos períodos, em resposta ao histórico da oscilação desse nível (DELIN et al., 2007). Além disso, o método assume que a recarga de águas subterrâneas é um evento pontual, não levando em conta o fluxo lento e estável que pode vir a ocorrer em algumas áreas com a zona não saturada mais grossa.

As análises da recarga foram conduzidas no programa computacional ESPERE (LANINI et al., 2016). A partir dos gráficos gerados foi possível extrapolar as linhas de recessão para cada declínio na oscilação do nível freático. As estimativas das recargas parciais foram obtidas através da diferença entre o pico da elevação do nível freático e o último valor da linha extrapolada, vezes o valor do rendimento específico do SAB, que foi obtido na literatura em Velásquez et al. (2008), que encontrou o valor de $12 \%$.

\section{Espacialização das taxas de recarga}

O método utilizado para mapear a recarga estimada para cada ano hidrológico seguiu os trabalhos de Stein et al. (1991) e Becchini et al. (2000) que propuseram calcular primeiro/interpolar depois os resultados do modelo de dado. Assim, foram calculadas as recargas pontuais para cada poço analisado na área de estudo e posteriormente interpoladas pelo método do Inverso do Quadrado das Distâncias (Inverse Distance Weighting - IDW). Trata-se de um método determinístico onde os dados não amostrados são obtidos a partir da distância ponderada até os valores amostrados (MELLO et al., 2003; 
HU et al., 2013; HARMAN et al. 2016; e SWAIN e PRATA, 2017). As Equações 2, 3 e 4 sintetizam como o ponto desconhecido é estimado:

$$
\begin{aligned}
& d_{i j}=\sqrt{\left(x_{i}-x_{j}\right)^{2}+\left(y_{i}-y_{j}\right)^{2}} \\
& P m_{i}=\frac{\sum_{j=1}^{N P} \frac{P_{j}}{\left(d_{i j}\right)^{b}}}{\sum_{j=1}^{N P} \frac{1}{\left(d_{i j}\right)^{b}}} \\
& P m=\frac{\sum_{i=1}^{N C} P m_{i}}{N C}
\end{aligned}
$$

em que $d_{i j}$ é a distância entre dois pontos $x_{i}$ e $x_{j}$ conhecidos, utilizada para estimar o ponto $P_{m}, N P$ é 0 número de pontos conhecidos, $N C$ é o número de células a serem estimadas, e $b$ é uma potência normalmente próxima de 2 no método do inverso do quadrado da distância. Nesse estudo a potência escolhida foi 2, configurando o atual método, como o inverso do quadrado das distâncias. Para esse procedimento utilizou-se o sistema de informações geográficas QGIS (www.qgis.org).

\section{RESULTADOS E DISCUSSÃO}

A Tabela 1 reúne as estatísticas descritivas dos 30 anos de registros de precipitação e das recargas calculadas para os dois anos hidrológicos estudados. O valor médio de precipitação nos trinta anos analisados foi de 1.548,29 mm. A partir da análise dos dados históricos de precipitação registrados entre setembro de 1987 e agosto de 2017 verificou-se que os anos em questão nos quais foram calculadas as recargas tiveram os volumes totais precipitados inferiores ao $1^{\circ}$ quartil $(1.397,25 \mathrm{~mm})$ no caso de $1.325,60 \mathrm{~mm}$ em 2014/2015 e acima do $3^{\circ}$ quartil (1.692,25 mm) no caso 1.805,00 mm em 2015/16, sendo assim considerados anos atípicos. O ano hidrológico 2014/2015 foi considerado mais seco e o ano hidrológico 2015/2016 foi considerado mais chuvoso. Os valores da precipitação registrados para 2014/2015 e 2015/16, assim como os percentuais relativos às recargas em cada um dos períodos podem ser encontrados na Tabela 2. Esses valores de precipitação encontram-se inclusive fora do intervalo constituído pelo valor da média mais ou menos o desvio padrão que foi de 232,81 mm. 


\begin{tabular}{lccc}
\hline & $P(\mathrm{~mm}) 1987 / 2017$ & $R(\mathrm{~mm}) 2014 / 2015$ & $R(\mathrm{~mm}) 2015 / 2016$ \\
\hline Média & $1.548,29$ & 211,13 & 276,33 \\
Mínimo & $1.085,00$ & 89,10 & 27,00 \\
$1^{\circ}$ quartil & $1.397,25$ & 171,10 & 186,72 \\
Mediana & $1.532,50$ & 199,90 & 261,00 \\
$3^{\circ}$ quartil & $1.692,25$ & 253,40 & 349,40 \\
Máximo & $2.088,00$ & 404,50 & 834,90 \\
Desvio Padrão & 232,81 & 77,43 & 146,05 \\
Variância & $54.198,29$ & $5.994,88$ & $21.330,76$ \\
Assimetria & 0,35 & 0,65 & 1,20 \\
Curtose & $-0,05$ & 0,48 & 3,15 \\
\hline
\end{tabular}

Tabela 1. $\mathrm{P}=$ precipitação em milímetros; $\mathrm{R}=$ recarga em milímetros.

$P=$ precipitação em milímetros; $R=$ recarga em milímetros

\begin{tabular}{lcc}
\hline & $2014-2015$ & $2015-2016$ \\
\hline$P(\mathrm{~mm})$ & $1.325,60$ & $1.805,00$ \\
$R(\mathrm{~mm})$ & 211,13 & 276,30 \\
$R / P(\%)$ & 15,92 & 15,31 \\
\hline
\end{tabular}

Tabela 2. Relação entre as precipitações registradas e as recargas calculadas na área de estudo para os anos hidrológicos de $2014 / 2015$ e $2015 / 2016$.

$P=$ precipitação em milímetros; $R=$ recarga em milímetros; $R / P=$ relação percentual entre o volume da recarga e o volume precipitado

A Figura 3 mostra a distribuição de frequência dos dados de precipitação, na forma de histograma e boxplot. Os resultados mostram que os dados analisados distribuem-se normalmente em torno da média, sem dados discrepantes ou espúrios (fora de padrão - "outliers"), caracterizando bem o regime de chuvas da região nas últimas 3 décadas. Observando-se também os valores de assimetria e curtose das séries de precipitação e das recargas estimadas pode-se considera-las como distribuições normais, com uma leve assimetria e alongamento no centro no caso da recarga de 2015/2016.
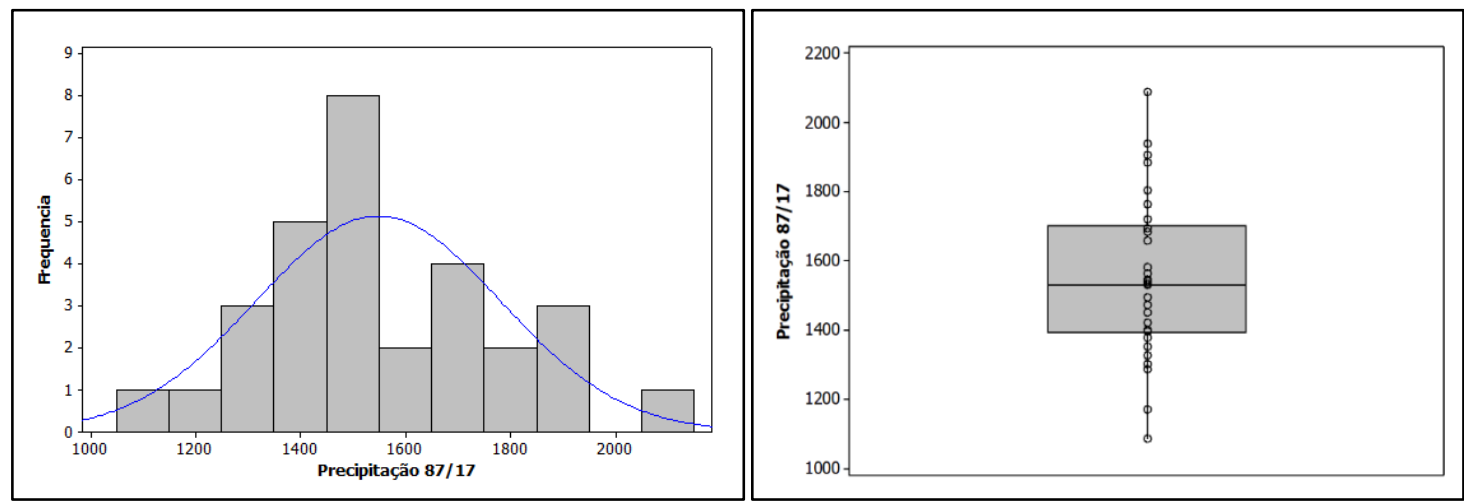

Figura 3. Histograma (esquerda) e box-plot (direita) dos dados históricos de precipitação registrados na Estação Ecológica de Santa Bárbara entre setembro de 1987 e agosto de 2017. 
Os dados de oscilação dos níveis freáticos foram interpolados para se obter os valores diários da altura freática no período analisado. Com os dados diários foi possível elaborar gráficos para ilustrar a oscilação nos níveis. Visualmente já foi possível notar um aumento nos níveis do primeiro para o segundo ano hidrológico, e isso se torna um padrão no trabalho, visto que esse comportamento aparece na maior parte da amostragem dos poços. Isso se deve ao comportamento da precipitação na área analisada, que também aumentou de 1.325,60 $\mathrm{mm}$ para 1.805,00 mm entre os anos hidrológicos. Houve um aumento de $26,56 \%$ na precipitação entre um ano hidrológico e o outro.

As estimativas parciais foram reunidas em estimativas anuais para os dois anos hidrológicos analisados. Ao compararmos esses valores com os dados de precipitação, obtivemos os valores de precipitação que se tornam recargas, chamados de percentuais de recarga/precipitação como observado na Tabela 2.

Para cada ano hidrológico foi elaborado um mapa para espacializar a recarga. A Figura 4 mostra a espacialização dos dados de recarga no ano hidrológico 2014/2015. Neste mapa verificam-se quatro regiões com maiores quantidades de recarga e uma região com menor recarga no centro da área. Isso pode estar ocorrendo por dois fatores, segundo o modelo hidrogeológico conceitual da área de estudo (SANTAROSA e MANZIONE, 2017). O primeiro é que a Estação Ecológica está sobre um divisor de águas que delimita quatro bacias hidrográficas, o que explica a menor recarga na área central, visto que há um grande escoamento para as áreas periféricas da área. O segundo fator é que a SP-280, a Rodovia Castelo Branco, passa pela área e a sua compactação pode criar uma barreira para a água escoar seja superficial ou subsuperficialmente. 


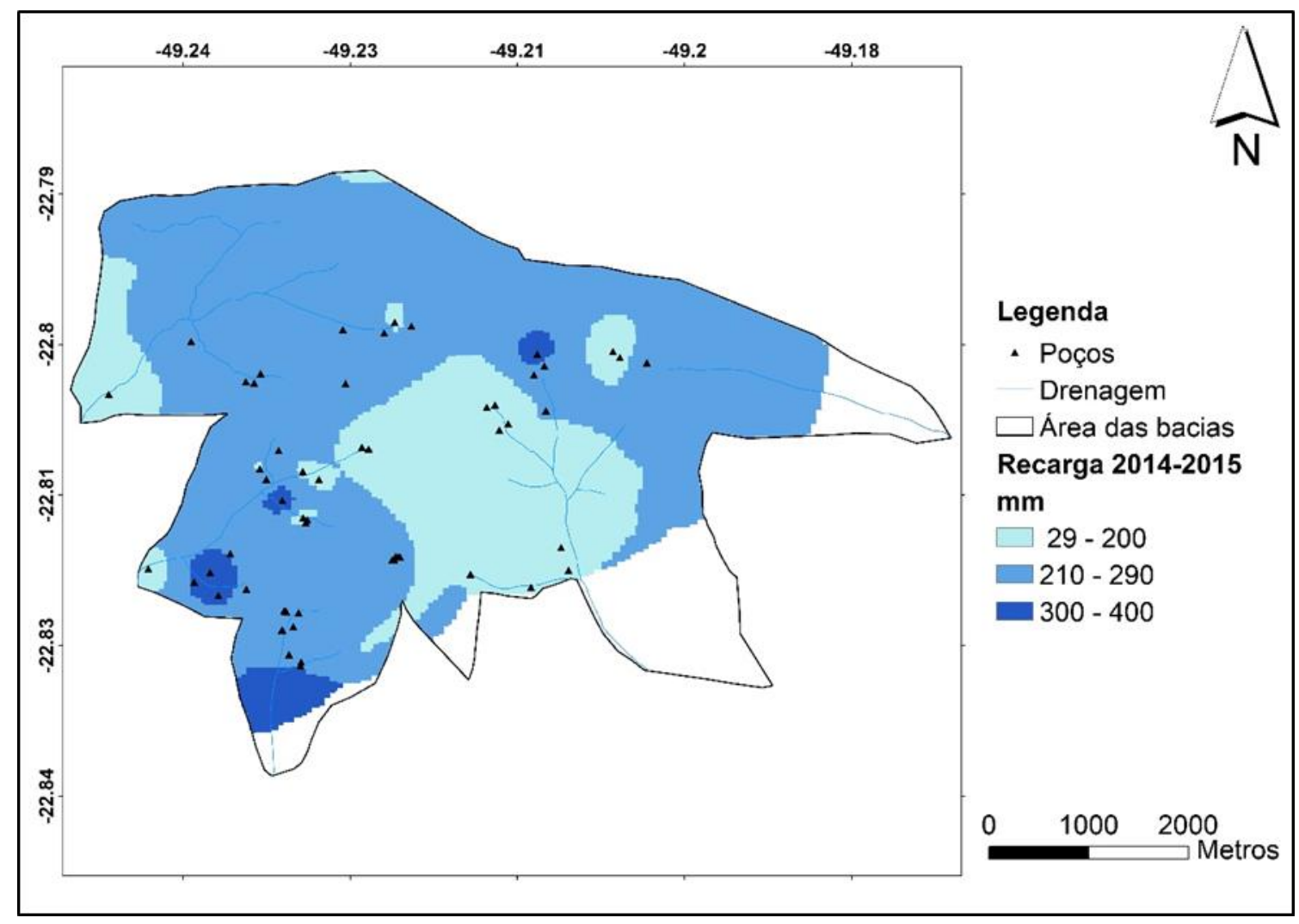

Figura 4. Mapa da recarga das águas subterrâneas (mm) estimado para o ano hidrológico 2014/2015 nas bacias estudadas na Estação Ecológica e Floresta Estadual de Santa Barbara.

Na Figura 5 pode-se observar a espacialização dos dados de recarga para o ano hidrológico 2015/2016. Neste mapa pode-se observar que houve um aumento no valor absoluto da recarga, entretanto observarse que o padrão visual se manteve. O aumento na precipitação, e consequentemente nos valores de recarga, pode ser explicado pelo fato de que o período subsequente ter sido marcado pelo fenômeno ENOS, ou seja, um período com aumento de chuvas. 


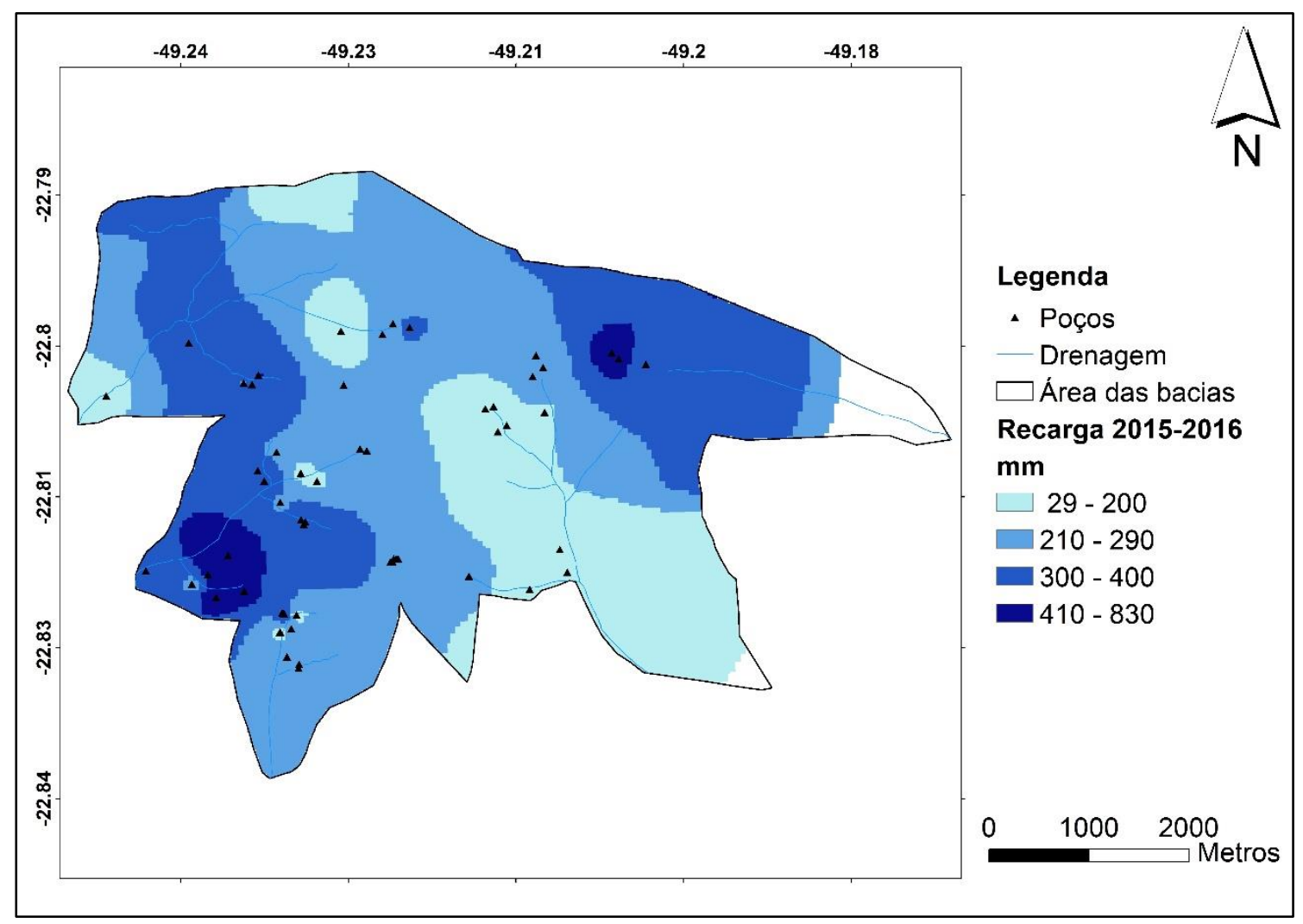

Figura 5. Mapa da recarga das águas subterrâneas (mm) estimado para o ano hidrológico 2015-2016 nas bacias estudadas na Estação Ecológica e Floresta Estadual de Santa Barbara.

E por fim, foi gerado um mapa com as diferenças espaciais entre as recargas calculadas de um ano para o outro, como pode ser observado na Figura 6 . As áreas com menores diferenças na recarga foram as áreas próximas as baixadas e drenagens da área de estudo que geralmente tendem ao alagamento como verificado nas observações do nível freático a campo. A zona não saturada nessas regiões também é menor, comportando um menor volume de recarga que nas áreas a montante e próximas aos divisores de água. Entretanto, o fato de estarem próximas a área úmidas ao Sul e Oeste da área de estudo faz com que essas áreas passem por diversos ciclo de recarga e descarga durante o ano, acumulando grandes volumes de água de recarga como visto nas Figura 4 e 5. Manzione (2017) verificou um aumento entre 0,72 cm e 1,61 m no nível freático no período estudado, sendo que o segundo ano apresentou um aumento mais pronunciado em todos os poços analisados. 


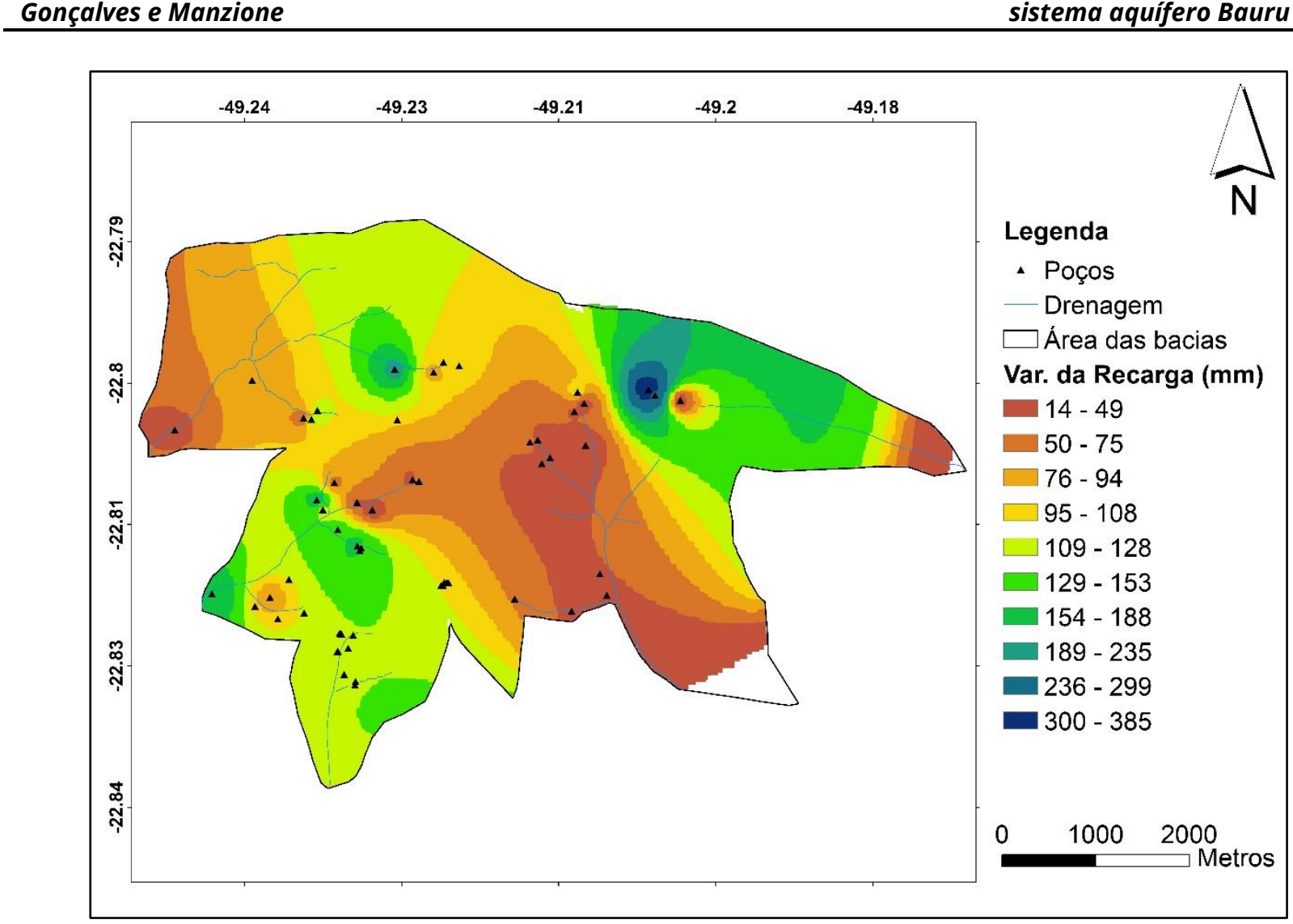

Figura 6. Mapa da diferença na recarga das águas subterrâneas (mm) entre os anos hidrológicos 2014/2015 e 2015/2016 nas bacias estudadas na Estação Ecológica e Floresta Estadual de Santa Barbara.

Em termos percentuais, o volume de precipitação que recarregou o SAB na área da EEcSB foi em torno de $15 \%$ para ambos períodos estudados. Quando analisadas as recargas em função do uso da terra, não houve diferenças evidentes entre as áreas de Cerrado e as áreas com reflorestamento com Pinus e Eucalipto. Lucas et al. (2012) apresentam a aplicação do método WTF em área de afloramento do Sistema Aquífero Guarani (SAG), utilizando dados de piezômetros localizados sob diferentes usos da terra, como cultivo de cana-de-açúcar, reflorestamento com eucalipto, citrus irrigado, em uma mesma bacia hidrográfica. O método foi eficiente para capturar as variações no período estudado, mostrando que tanto para o ano hidrológico de 2005/06 quanto para o ano hidrológico de 2010/11. Nesse estudo no SAG, os poços localizados em áreas de eucalipto apresentaram menores taxas recargas e os poços localizados em áreas de pastagens as maiores taxas de recarga, mesmo havendo uma diferença grande na precipitação anual (2005/2006 foi 50\% mais seco que 2010/2011), isso vai de acordo com Joshi e Palanisami (2011), onde os autores dizem que a cultura do Eucalipto deve ter sugado mais água de camadas mais profundas, o que levou à uma perturbação na recarga do estudo, ou como em Dean et al. (2015), onde os autores observaram uma diminuição no nível da água e atribuem esse fenômeno ao 
possível maior uso de água pela cultura, quando comparada com a pastagem no mesmo estudo. Isso denota uma grande diferença em termos de consumo hídrico entre cultivos agrícolas e florestais. Assim como no presente estudo, Silva e Manzione (2016) também não perceberam diferenças no comportamento dos níveis em poços em área com Pinus e sem Pinus da EEcSB, sugerindo que as diferenças ocorrem muito mais por diferenças hidrogeológicas e geomorfológicas, como linhas de fluxo e relevo, respectivamente, do que do uso da terra propriamente dito. Para resultados mais conclusivos sobe a influência da vegetação recomenda-se continuar o monitoramento das áreas para que os efeitos do manejo da vegetação e das florestas possam ser capturados na análise da recarga em períodos subsequentes.

\section{CONCLUSÃO}

A partir dos resultados deste trabalho pode-se verificar que:

- no ano hidrológico de 2015/2016, considerado mais chuvoso, o volume de recarga foi maior que no ano hidrológico de 2014/2015, considerado mais seco;

- o ano hidrológico de 2015/2016 apresentou um volume de precipitação 26, 65\% maior que no ano hidrológico anterior de 2014/2015 em decorrência do fenômeno ENOS;

- independe do montante de precipitação, a fração de água que se torna recarga é percentualmente próxima de um ano para o outro, em torno de 15-16\%;

- a espacialização da recarga permitiu verificar o comportamento do lençol freático em áreas ocupadas por vegetação de Cerrado e por reflorestamentos com Pinus e Eucalipto e termos de volume recuperado, sem encontrar diferenças evidentes decorrentes do uso da terra;

- estudos que envolvam o uso de geoinformação associada a técnicas que permitam extrair dos dados padrões e tendências presentes nos fenômenos em estudo podem refinar e incorporar novas percepções à análise geoambiental.

\section{AGRADECIMENTOS}


A FAPESP (Fundação de Amparo a Pesquisa do Estado de São Paulo) pelos recursos disponibilizados para execução dessa pesquisa (Processos 2014/04524-7 e 2016/09737-4). A CAPES (Coordenação de Aperfeiçoamento de Pessoal de Nível Superior) pela bolsa de estudos concedida ao primeiro autor.

\section{REFERÊNCIAS}

BECCHINI, L.; DUCCO, G; DONATELLI, M.; STEIN, A. Modelling, Interpolation and Stochastic simulation in space and time of global solar radiation. Agriculture, Ecosystems and Environment, v. 81, p. 29-42, 2000.

BOULANGER, J. P; LELOUP, J.; PENALBA, O.; RUSTICUCCI, M.; LAFON, F.; VARGAS, W. Observed precipitation in the Paraná-Plata hydrological basin: long-term trends, extreme conditions and ENSO teleconnections. Climate Dynamics, v. 24 , p. $393-$ $413,2005$.

CBH-MP (Comitê de Bacia Hidrográfica do Médio Paranapanema). As águas do aquífero Bauru no Médio Paranapanema. Marília: Comitê de Bacia Hidrográfica do Médio Paranapanema, 2010. 20 p.

CEPAGRI (Centro de Pesquisas Meteorológicas e Climáticas Aplicadas a Agricultura). Clima dos Municípios Paulistas. Disponível em: <http://www.cpa.unicamp.br/outras-informacoes/clima-dos-municipios-paulistas.html>. Acesso em: 16 mar. 2016.

COELHO, C. A. S.; CARDOSO, D. H. F.; FIRPO, M. A. F. Precipitation diagnostics of an exceptionally dry event in São Paulo, Brazil. Theoretical and Applied Climatology, v. 125, p. 769-784, 2016.

COELHO, V. H. R.; MONTENEGRO, S.; ALMEIDA, C. N.; SILVA, B. B.; OLIVEIRA, L. M., GUSMÃO, A. C. V.; FREITAS, E. S.; MONTENEGRO, A. A. A. Alluvial groundwater recharge estimation in semi-arid environment using remotely sensed data. Journal of Hydrology, v.548, p.1-15, 2017.

CPRM (Serviço Geológico do Brasil). Domínio Geológico Litoestratográfico do Estado de São Paulo. São Paulo, 2006. Escala $1: 750.000$

CPRM (Serviço Geológico do Brasil). Acompanhamento da estiagem na região Sudeste do Brasil 2014 (RELATÓRIO 1 - Área de Atuação da Superintendência Regional da CPRM de São Paulo). São Paulo, 2014. 32 p.

CPRM (Serviço Geológico do Brasil). Acompanhamento da estiagem na região Sudeste do Brasil 2015 (RELATÓRIO 3 - Área de Atuação da Superintendência Regional da CPRM de São Paulo). São Paulo, 2015. 49 p.

DEAN, J. F.; WEBB, J. A.; JACOBEN, G. E.; CHISARI, R.; DRESEL, P. E. A groundwater recharge perspective on locating tree plantations within low-rainfall catchments to limit water resource losses. Hidrology and Earth System Sciences. V. 19, p.1107-1123, 2015.

DELIN, G. N.; HEALY, R. W.; LORENZ, D. L.; NIMMO, J. R. Comparison of local- to regional-scale estimates of groud-water recharge in Minnesota, USA. Journal of Hydrology, v. 334. p. 231-249, 2007.

FERRER, N.; FOLCH, A.; LANE, M.; OLAGO, D.; ODIDA, J.; CUSTÓDIO, E. Groundwater hydrodynamics of an Eastern Africa coastal aquifer, including La Niña 2016-17 drought. Science of the Total Environment, v. 661, p.575-597, 2019.

GEMITZI, A.; AJAMI, H.; RICHNOW, H. Developing empirical monthly groundwater recharge equations based on modeling and remote sensing data - Modeling future groundwater recharge to predict climate change impacts. Journal of Hydrology, v.546, p.1-13, 2017. 
HAN, D.; CURREL, M. J.; CAO, G.; HALL, B. Alterations to groundwater recharge due to anthropogenic landscape change. Journal of Hydrology, v. 554, p. 545-557, 2017.

HARMAN, B. I.; KOSEOGLU, H.; YIGIT, C. O. Performance evaluation of IDW, Kriging and multiquadric interpolation methods in producing noise mapping: A case study at the city of Isparta, Turkey. Applied Acoustics, v.112, p.147-157, 2016.

HEALY, R. W. Estimating groundwater recharge. United Kingdom: Cambridge University Press, 2010. 245p., CFC-12 and ${ }^{3} \mathrm{H}$ chemistry. Journal of Hydrology, v.409, n. 3-4, p.650-662, 2011.

HOCKING, M.; KELLY, B. F. J. Groundwater recharge and time lag measurement through vertsols using impulse response functions. Journal of Hydrology, v.535, p.22-35, 2016.

HU, S.; SHENG, Q.; WANG, L.; XU, D. Modeling land price distribution using multifractal IDW interpolation and fractal filtering method. Landscape and Urban Planning, v.110, p.25-35, 2013.

JOSHI, M.; PALANISAMI, K. Impact of eucalyptus plantations on ground water availability in south Karnataka. ICID 21st International Congress on Irrigation and Drainage, Tehran,15-23 October, 2011.

KEESARI, T.; SHARMA, D. A.; RISHI, M. S.; PANT, D.; MOHOKAR, H. V.; JARYAL, A. K.; SINHA, U. K. Isotope investigation on groundwater recharge and dynamics in shallow and deep alluvial aquifers of southwest Punjab. Applied Radiation and Isotopes, v.129, p.163-170, 2017.

LANINI, S.; CABALLERO, Y.; SEGUIN, J. J.; MARÉCHAL, J. C. ESPERE- A Multiple-Method Microsoft Excel Application for Estimating Aquifer Recharge. Ground water, v. 54, p. 155-156, 2016.

LUCAS, M. C.; GUANABARA, R. C.; WENDLAND, E. Estimativa de recarga subterrânea em área de afloramento do Sistema Aquífero Guarani. Boletín Geológico y Minero, v. 123, p. 311-323, 2012.

LUCAS, M. C.; WENDLAND, E. C. Recharge estimates for various land uses in the Guarani Aquifer System outcrop area. Hydrological Sciences Journal, v. 61, p. 1253-1262, 2016.

MANZIONE, R. Águas Subterrâneas: Conceitos e Aplicações sob uma visão multidisciplinar. Jundiaí: Paco Editorial, 2015.383 p.

MANZIONE, R. L. Impactos do clima no comportamento de níveis freáticos em área de conservação utilizando um modelo autoregressivo de séries temporais. Brazilian Journal of Biosystems Engineering, v. 11, p. 185-198, 2017.

MARÉCHAL, J. C.; DEWANDEL, B.; AHMED, S.; GALEAZZI, L.; ZAIDI, F. K. Combined estimation of specific yield and natural recharge in a semi-arid groundwater basin with irrigated agriculture. Journal of Hydrology, v. 319, n.1-2, p.281-293, 2006.

MELO, A. C. G.; DURIGAN, G. Plano de manejo da Estação Ecológica de Santa Bárbara. São Paulo: Instituto Florestal, 2011. $222 \mathrm{p}$.

MELLO, C. R.; LIMA, J. M.; SILVA, A. M.; MELLO, J. M.; OLIVEIRA, M.S. Krigagem e inverso do quadrado da distância para interpolação dos parâmetros da equação de chuvas intensas. Revista Brasileira de Ciência do Solo, v. 27, p. 925-933, 2003.

MOON, S.; WOO, N.; LEE, K. Statistical analysis of hydrographs and water-table fluctuation to estimate groundwater recharge. Journal of Hydrology, v. 292, n. 1-4, p.198-209, 2004.

NIAZI, A.; BENTLEY, L.R.; HAYASHI, M. Estimation of spatial distribution of groundwater recharge from stream baseflow and groundwater chloride. Journal of Hydrology, v.546, p.380-392, 2017.

PENALBA, O. C.; PÁNTANO, V. C.; SPESCHA, L. B.; MURPHY, G. M. ENSO impact on dry sequences during different phenological periods in the east-northeast of Argentina, In: III International Conference on ENSO: Bridging the gaps between global ENSO science and regional processes, extremes and impacts, Guayaquil, Ecuador, 12-14 November, 2014.

PENALBA, O. C.; RIVERA, J. A. Precipitation response to El Niño/La Niña events in Southern South America - emphasis in regional drought occurrences. Advances in Geosciences, v. 42, p. 1-14, 2016. 
PODESTÁ, G. P.; MESSINA, C. D.; GRONDONA, M. O.; MAGRIN, G. O. Associations between grain crop yields in central-eastern Argentina and El Niño-Southern Oscillation, Journal of Applied Meteorology, v. 38, p. 1488-1498, 1999.

ROSS, J. L. S.; MOROZ, I. C. Mapa geomorfológico do Estado de São Paulo. Revista do Departamento de Geografia, v. 10, p. 41$56,1996$.

SANTAROSA, L. V. Mapeamento de níveis freáticos do Sistema Aquífero Bauru (SAB) em área de proteção ambiental em Águas de Santa Bárbara/SP durante o ano hidrológico 2014/15. 124 p. 2016. Dissertação (Mestrado em Agronomia - Irrigação e Drenagem) - Faculdade de Ciências Agronômicas, Universidade Estadual Paulista, Botucatu, 2016.

SANTAROSA, L. V.; MANZIONE, R. L. Modelo Hidrogeológico Conceitual da Estação Ecológica de Santa Bárbara (EEcSB) em área do Sistema Aquífero Bauru (SAB). Águas Subterrâneas, v. 30, p. 362-374, 2016.

SCANLON, B. R.; HEALY, R. W.; COOK, P. G. Choosing appropriate techniques for quantifying groundwater recharge.

Hydrogeology Journal, v. 10, n. 2. p. 18-39. 2002.

SILVA, R. C. F. da; MANZIONE, R. L. Aplicação do modelo Hartt no estudo das oscilações dos níveis freáticos do Sistema Aquífero Bauru (SAB) sob vegetação de cerrado. Águas Subterrâneas, v. 31, p. 404-412, 2017.

SPESCHA, L.; FORTE LAY, J.; SCARPATI, O.; HURTADO, R. Los excesos de agua edáfica y su relación con el ENSO en la región Pampeana. Rev. Facultad de Agronomía, v. 24, p. 161-167, 2004.

STEIN, A.; STARITISKY, G.; BOUMA, J. simulation of moisture deficits and areal interpolation by universal cokriging. Water Resources Research, v. 27, p. 1963-1973, 1991.

SUSILO, G. E.; YAMAMOTO, K.; IMAI, T. Modeling Groundwater Level Fluctuation in the Tropical Peatland Areas under the Effect of El Nino. Procedia Environmental Sciences, v. 17, p.119-128, 2013.

SWAIN, J. B.; PATRA, K. C. Streamflow estimation in ungauged catchments using regionalization techniques. Journal of Hydrology, v. 554, p. 420-433, 2017.

TABAU, I.; VÁZQUEZ-SUÑÉ, E.; CARRERA, J.; VALHONDO, C.; CRIOLLO, R. Quantification of groundwater recharge in urban environments. Science of the total environment, v. 592, p.391-402, 2017.

VALENTE, O. F.; GOMES, M. A. Conservação de nascentes. Hidrologia e manejo de bacias de cabeceira. Viçosa: Editora Aprenda Fácil, 2005. 210 p.

VELÁSQUEZ, L. M. N.; BRANCO, O. E. A.; CARVALHO FILHO, C. A.; MINARDI, P. S. P.; COTA, S. D. S.; BOMTEMPO, V. P.; CAMARGOS, C. C.; RODRIGUES, P. C. H.; FIUMARI, S. L. Caracterização hidrogeológica dos aquíferos Bauru e Serra Geral e avaliação das reservas do aquífero Bauru no município de Araguari, Minas Gerais. XV Congresso Brasileiro de Águas Subterrâneas, 2008.

WANG, P.; GRINEVSKY, S.O., POZDNIAKOV, S. P., YU, J.; DAUTOVA, D. S.; MIN, L.; DU, C.; ZHANG, Y. Application of the water table fluctuation method for estimating evapotranspiration at two phreatophyte-dominated sites under hyper-arid environments. Journal of Hydrology, v. 519, p. 2289-2300, 2014. 